\title{
CEREBRAL SINUS THROMBOSIS IN CHILDREN
}

\author{
BY \\ J. H. EBBS, M.D., D.C.H., \\ The Children's Hospital, Birmingham.
}

Thrombosis of the cerebral venous sinuses has been recognized for many years. The first description is credited to Morgagni $^{1}$ in 1717 , and Abercrombie $^{2}$ made the first accurate study of the condition. It is usually classified as primary or secondary. The primary type is described as occurring with marasmus, dehydration, gastro-enteritis and anaemia; whereas the secondary type is always associated with infection, chiefly of the middle ear and mastoid region, and although it is a not uncommon sequel of infection spreading from the face, scalp, skull bones or meninges, it rarely follows trauma to the skull. Recently Ehlers and Courville ${ }^{3}$ have described a combined type which is found in marantic, dehydrated infants with otitis media. Holt and McIntosh ${ }^{4}$ state that, 'it is customary to distinguish between inflammatory or septic thrombosis and a so-called marantic or cachetic type. In the former, obvious inflammatory changes are found in the thrombus; in the latter, evidences of inflammation are inconspicuous. Infection in some part of the body is always present, however, and even here it is probably of etiological significance.'

Byers and Hass ${ }^{5}$ give a complete review of the subject while reporting fifty cases which had been observed in Boston during a period of six years. They found twenty-six cases associated with infection and twenty-four which they classified as primary, one half of the latter occurring in August, September and October. Sixteen of the twenty-four cases showed a severe unexplained diarrhoea. Acute dehydration was a more important factor in these cases than malnutrition. Wyllie ${ }^{6}$ has described three cases at the Hospital for Sick Children, Great Ormond Street, two of which were associated with pneumonia and one with infantile diarrhoea. He classifies the origin of the disease as otitic and marantic. The latter group includes those cases secondary to infantile diarrhoea, prolonged suppuration, tuberculosis, carcinoma, pertussis, chlorosis, empyema, pneumonia, appendicitis, cerebral tumour, infectious diseases and following operations. Ehlers and Courville ${ }^{3}$ have reviewed the literature and have collected sixty cases of primary thrombosis of the internal cerebral veins. In the majority the thrombosis of the internal cerebral vessels was associated with a similar condition of the cerebral venous sinuses. Twenty-one of these cases occurred in infants or children. Simpson ${ }^{7}$ analyzed forty-two cases of thrombosis of the cerebral vessels which had been found at the Hospital for Sick Children, Toronto, during a period of ten years. Some text-books of diseases of children do not mention the condition, whilst others refer only to thrombosis associated with mastoid infection. Some state that symptoms may be entirely lacking, the condition being found post mortem 
in association with some other process. The usual picture described, however, is one of marked septic symptoms, i.e., chills, high temperature, headache and meningeal signs. Osler ${ }^{8}$ described the syndrome of mental dullness, headache, convulsions, vomiting and paralysis. If the superior longitudinal sinus is affected paralysis of the legs may be the diagnostic point since the cortical supply to the legs is close to the superior longitudinal sinus. Recovery rarely occurs under these conditions and when it does a permanent spastic paralysis of the legs usually results.

Thrombosis of the cerebral vessels in children is not usually considered as a common occurrence, but during the past two years fourteen patients have been admitted to the Birmingham Children's Hospital suffering from this condition. The records of the hospital for the previous twelve years show that only eighteen cases had been found. It would therefore appear that there has been an increase in the incidence of the disease, but it still remains as an entity which is seldom considered in the differential diagnosis of cerebral conditions in young children. It is important if possible to diagnose the condition during life, and a review of several recent cases brings out many points which have been found of some value in achieving this end.

\section{Case records}

A summary of the age, etiology and important clinical and pathological findings has been made of the thirty-two cases recorded in this hospital during a period of fourteen years (table 1). The case records of eight patients are appended, and the fourteen cases observed in the past two years form the basis of the remarks which follow.

Case 19. M. O., a girl, aged two years, was well until two days before admission, when she became restless and tired. Her breathing became rapid

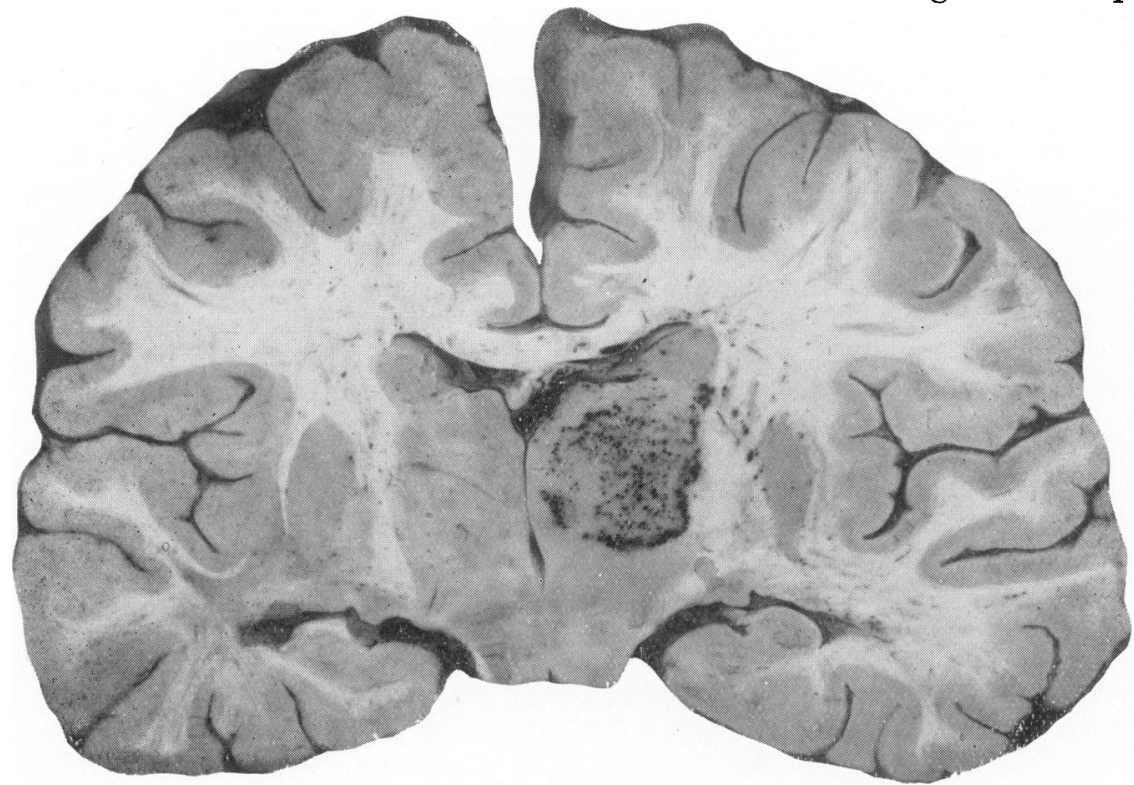

Fic. 1. Case 19. M. O.-Thrombosis of the internal cerebral vessels resulting in hemiplegia. 


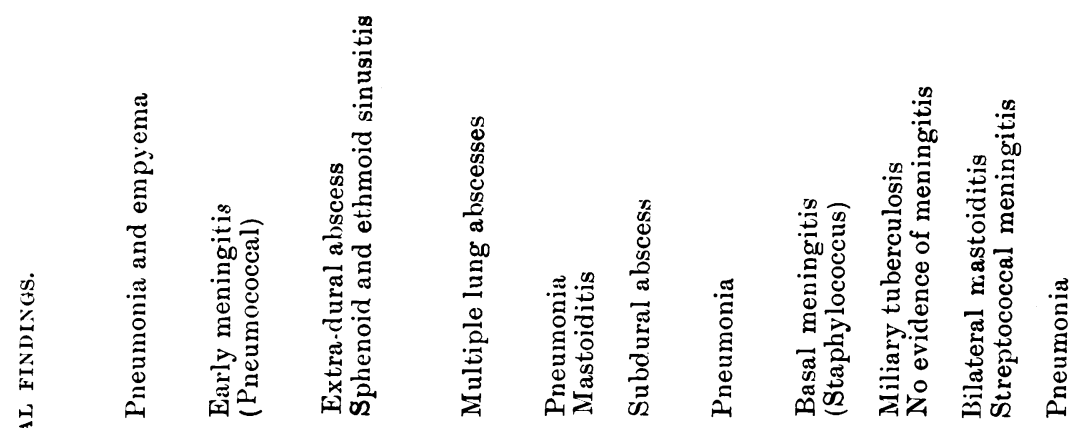

స్ّ

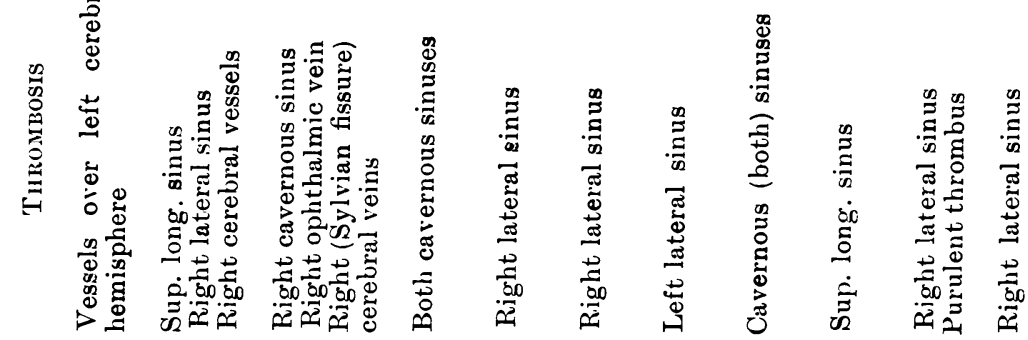

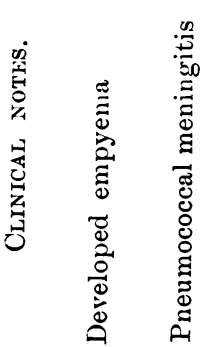

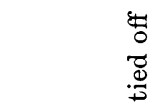

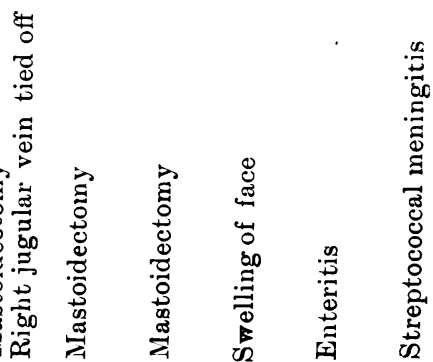

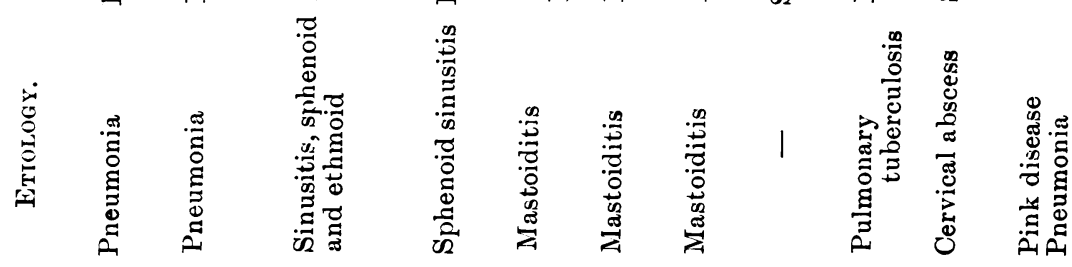

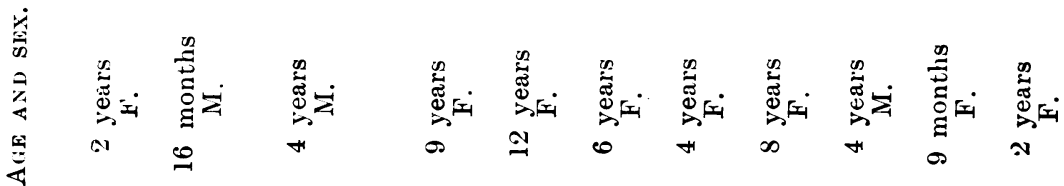

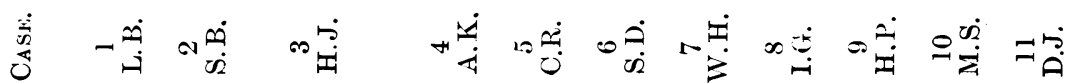




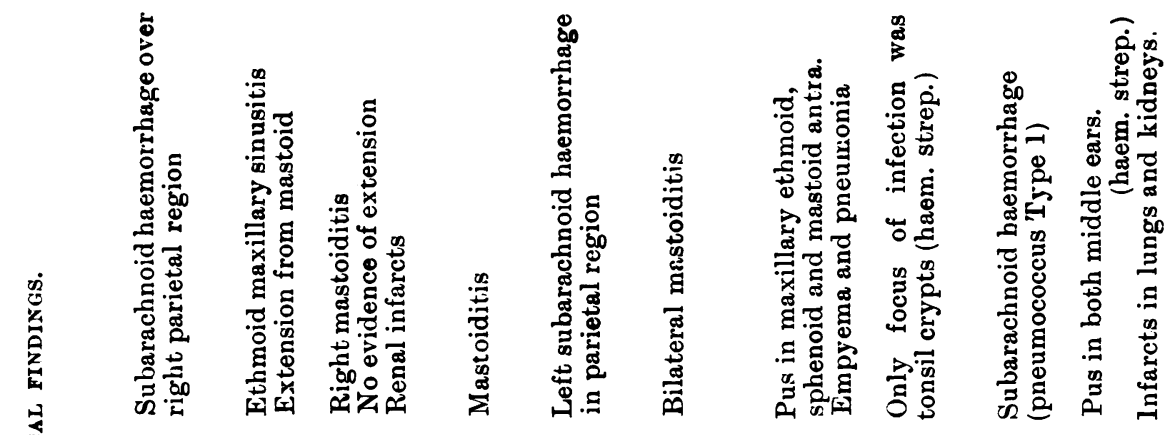

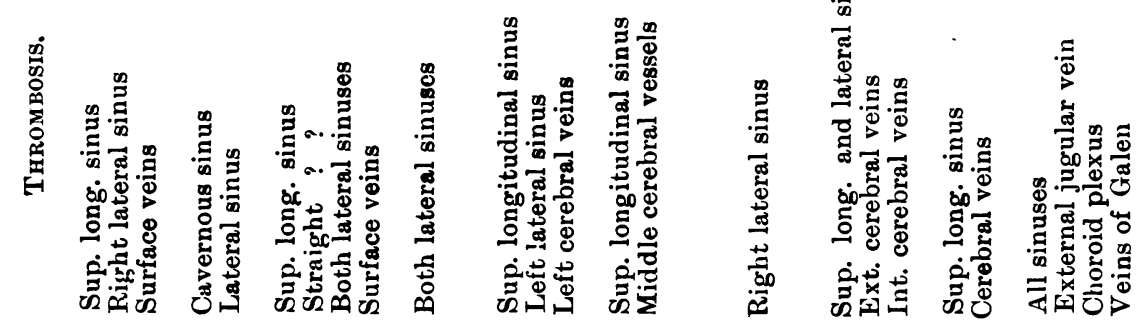

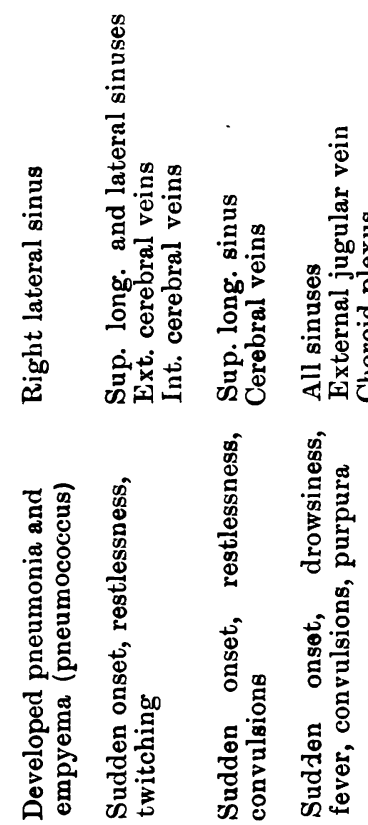

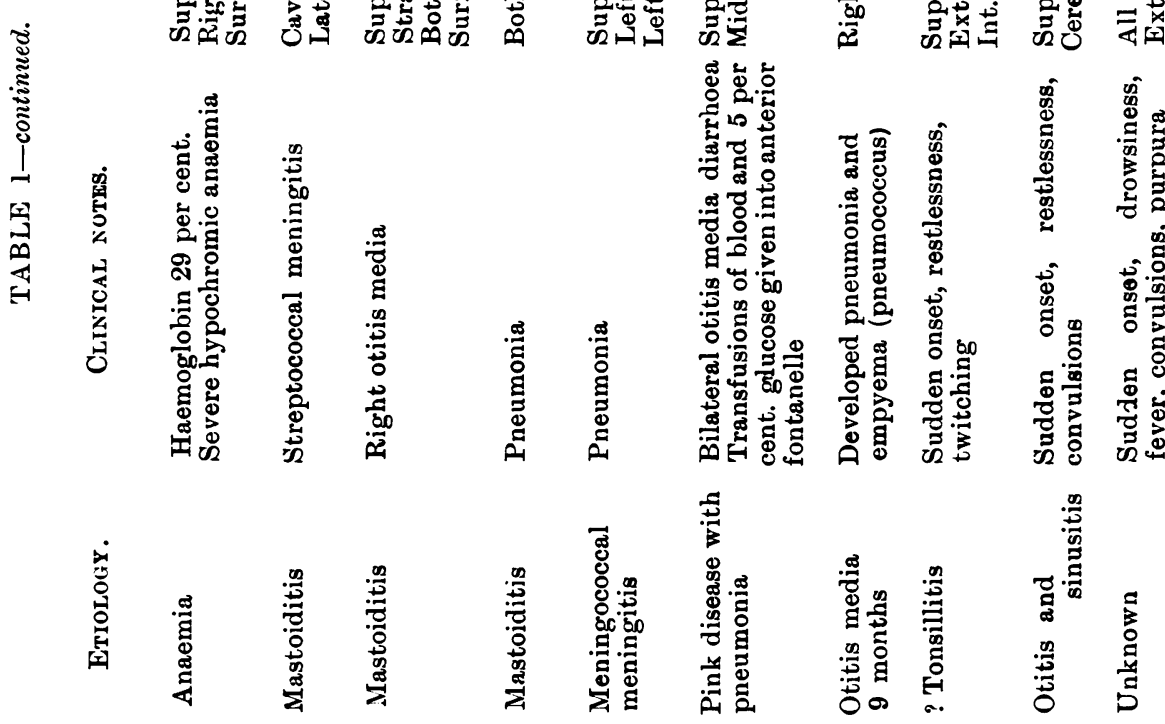




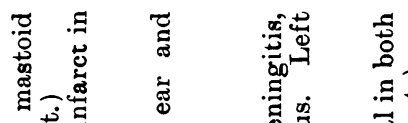

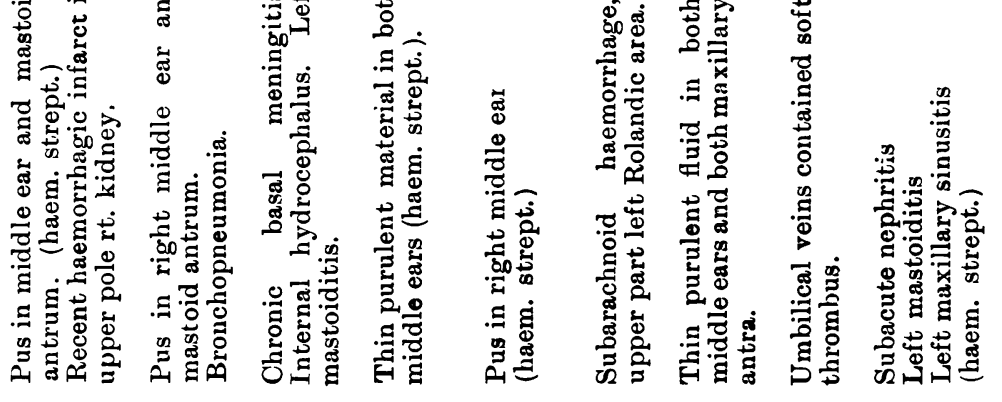

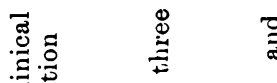

पे

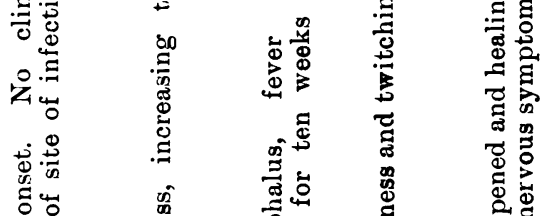

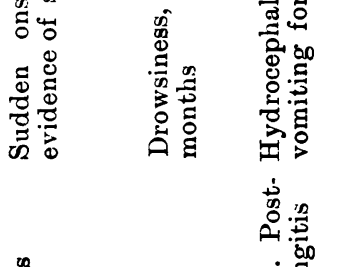

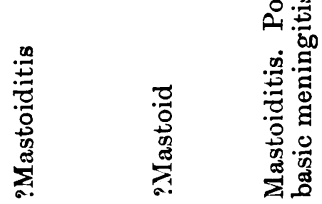

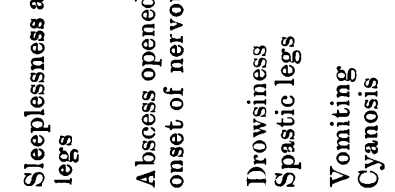

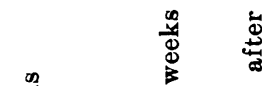

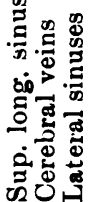

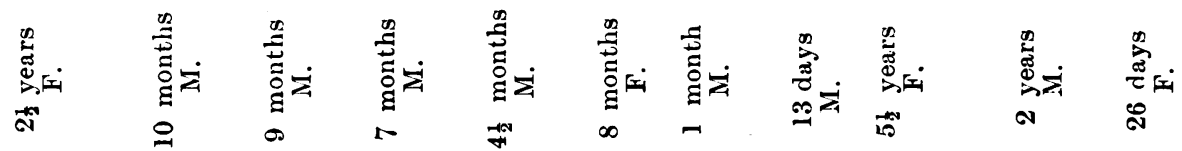

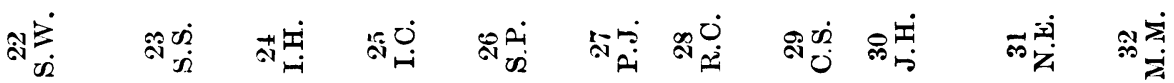


and she lapsed into unconsciousness in two or three hours. Twitching of the arms and legs was then noticed. She regained consciousness in a short time and vomited. Later in the day the child had a definite convulsion and remained unconscious after the seizure. The morning after the onset the right arm and leg were found to be weak. She was feverish from the onset and the temperature remained about $102^{\circ} \mathrm{F}$. throughout. Convulsive twitchings of the right side of the body continued after admission to the hospital. A lumbar puncture revealed 1,000 creneated red blood cells per c.mm. with no increase of white blood cells. Cultures were sterile. A blood count showed 24,800 leucocytes with 81 per cent. polymorphonuclears and evidences of slight toxic changes. Twitching of the right arm and leg continued throughout the next four days. The fifth day after admission she seemed improved and took feeds well, but the following day she became drowsy and was very difficult to arouse. There was a slight stiffness of the neck, stertorous breathing and an irregular pulse. Spasticity of all her limbs developed. Her condition had rapidly become worse. A trephining operation was done over the left meningeal area because cerebral haemorrhage, tumour or abscess had to be considered in the differential diagnosis of a child who was becoming rapidly worse. At operation nothing was found beyond congestion and increased pressure. The following day the child could not swallow, there was marked general rigidity, and she died eleven days after the onset. A summary of the cerebro-spinal fluid findings is shown in the following table.

TABLE 2.

Cerkbro-spinal fluid findings in case 19.

\begin{tabular}{|c|c|c|c|c|c|}
\hline 1) & $\begin{array}{c}\text { Leucocytes } \\
\text { per c.mm. }\end{array}$ & $\begin{array}{l}\text { RED BLOOD CELLS } \\
\text { per c. mm. }\end{array}$ & $\begin{array}{c}\text { Sugar } \\
\text { per cent. }\end{array}$ & $\begin{array}{l}\text { CHLORIDES } \\
\text { per cent. }\end{array}$ & $\begin{array}{l}\text { Protein } \\
\text { per cent. }\end{array}$ \\
\hline 1 & 6 & 1,000 & $56 \mathrm{mgm}$. & $876 \mathrm{mgm}$. & 90 mgm. \\
\hline 2 & 18 & 1,500 & - & - & - \\
\hline 5 & 5 & $\begin{array}{c}\text { Slightly } \\
\text { xanthochromic }\end{array}$ & - & - & - \\
\hline 8 & 8 & , & - & 932 mgm. & $125 \mathrm{mgm}$. \\
\hline
\end{tabular}

Post-mortem examination revealed a terminal broncho-pneumonia of the lower lobes of both lungs. The brain was markedly congested; all of the superficial blood vessels were thrombosed, also the vessels in the substance of the brain, chiefly on the left side in the region of the thalamus and internal capsule. All of the venous sinuses were thrombosed (see figure 1). The only focus of infection was a purulent exudate in the crypts of both tonsils which were hypertrophied. Post-mortem blood cultures and cultures of the thrombus in the superior longitudinal sinus remained sterile.

Case 20. J. B., a girl, aged sixteen months was admitted with a history of having been well until the day before admission, when she appeared flushed, became very restless and the following morning developed convulsions, which continued after admission to the hospital. The convulsive twitchings were at first generalized, but later became confined to the left side of the face, the left arm and leg. A lumbar puncture relieved the convulsions. The cerebro-spinal fluid was clear, was under increased pressure and contained 4 cells per c.mm., no sugar, chlorides 774 mgm. per cent., protein $13 \mathrm{mgm}$. per cent. On examination there was no neck rigidity, Kernig's sign was negative and the reflexes were normal. There was no evidence of infection. A blood culture remained sterile. The child continued to be very restless, resented being touched, and at times seemed to be semi-conscious, although she could take fluids. The temperature was normal and remained so until the day before her death, when it became 
elevated to $102^{\circ} \mathrm{F}$. The day after admission the left arm and leg became paralyzed, the neck became stiff and the Kernig sign was positive on both sides. The reflexes were absent on the left side. During the next four days her condition became rapidly worse. In the late stages of her illness bluish-black areas appeared on the neck, hands, ears and nose due to thrombosis or emboli in the terminal vessels. A fine purpuric rash was present over the lower legs and a few purpuric spots on the backs of the hands.

The child died nine days after the onset. In view of the sudden onset with convulsions and meningeal signs without cerebro-spinal fluid findings of meningitis, and experience with the previous case, a diagnosis of cerebral sinus thrombosis was made. At post-mortem examination the brain showed a diffuse gelatinous haemorrhagic area in the region of both Rolandic areas and extending over the cortex. This was more marked on the right side. All of the superficial veins and the superior longitudinal sinus were thrombosed (see figures 2 and 3). Purulent exudate was found in both

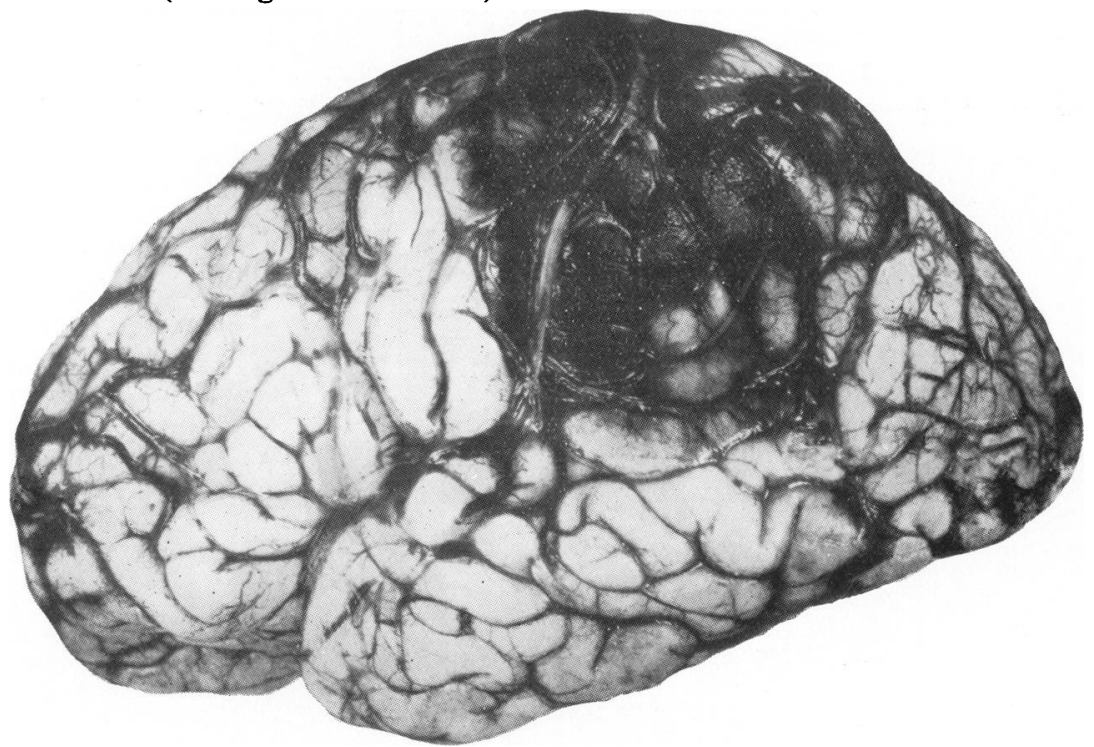

FIG. 2. Case 20. J. B.-Left cerebral hemisphere showing thrombosis superficial vessels and the associated subarachnoid haemorrhage.

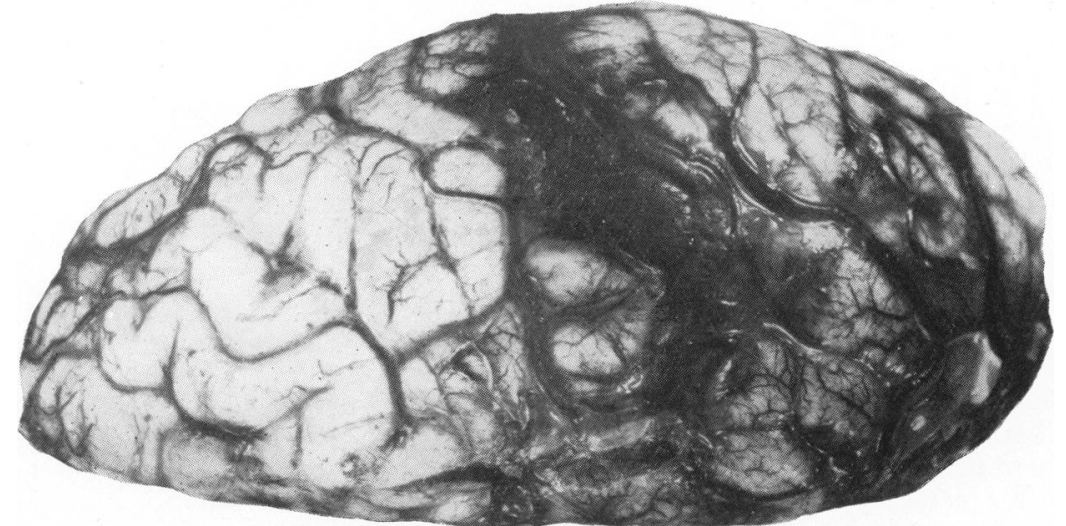

Fig. 3. Case 20. J. B.-Superior surface of right cerebral hemisphere. 
maxillary antra, ethmoid cells, middle ears and mastoid antra. This pus was cultured and grew pneumococcus type 1 , which was also cultured from the clot in the superior longitudinal sinus.

The above two cases were outstanding in their sudden onset without any evident infection during the course of illness. The cultures of pneumococcus in one case and the presence of a septic tonsillitis in the other are possible etiological factors.

Case 21. J. B., a girl, aged two years, was an only child of healthy parents, who was well until the day before admission, when she became feverish and was put to bed. At 3 a.m. she had a convulsion lasting about ten minutes, with frothing at the mouth, eyes rolled up and twitching of both arms and legs. At 6 a.m. she had a similar convulsion lasting twenty minutes which was followed by vomiting of brown frothy fluid and upper abdominal pain. She had not been in contact with any known infection. When examined upon admission to the hospital the child was rolling her head from side to side, but apart from this she showed no abnormal signs. The temperature was $105 \cdot 4^{\circ}$ F., pulse 160 and respirations 48 . The temperature remained elevated between $102^{\circ}$ and $103^{\circ} \mathrm{F}$. for one week.

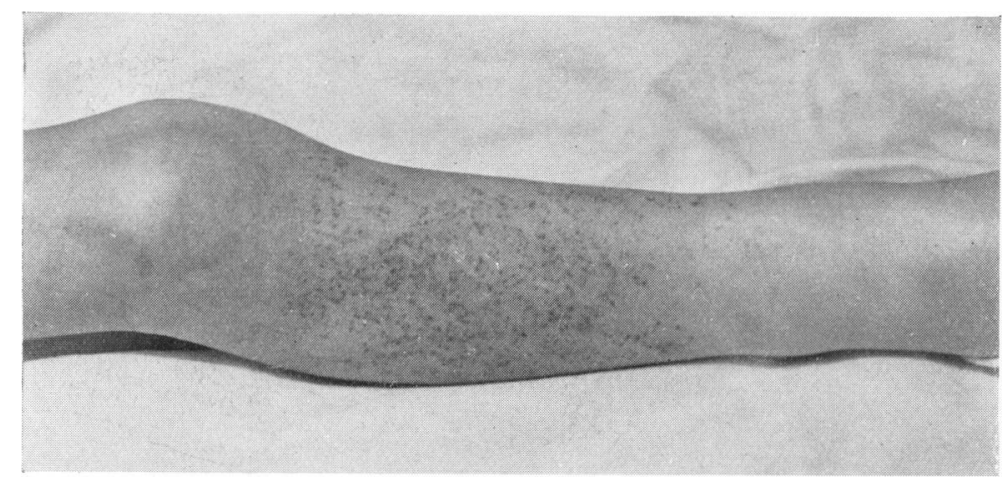

Fig. 4. Case 21. J. B.-Purpuric rash over right leg.

The only focus of infection was a mild pyelitis. The child vomited several times daily for the first week but only occasionally subsequently. Four days after admission the legs became hypertonic but there were no other signs of disturbance of the nervous system. It was later noted that the child appeared to be blind and she continually opened and closed her mouth. This was associated with clonic spasms of both upper limbs, the right arm and hand being more affected than the left. The legs were normal but a definite stiffness of the neck had developed. A lumbar puncture revealed 62 red blood cells per c.mm. and 6 white blood cells per c.mm. The cerebrospinal fluid sugar was $48 \mathrm{mgm}$. per cent., the chlorides $766 \mathrm{mgm}$. per cent. and the protein $23 \mathrm{mgm}$. per cent. The spinal fluid and urine were searched for tubercle baccilli but none were found and the Mantoux test was negative. The blood urea was $23 \mathrm{mgm}$. per cent. and the non-protein nitrogen $21 \mathrm{mgm}$. per cent. A blood culture remained sterile during five days' incubation. Cultures of the cerebro-spinal fluid were also sterile. The blood showed 90 per cent. of haemoglobin with normal colour index. The leucocytes numbered 7,700 per c.mm. and the differential count showed 20 per cent. of segmented polymorphonuclear cells and 40 per cent. non-segmented forms. The Wassermann reaction was negative. An x-ray examination of the lungs showed no evidence of pneumonia or tuberculosis. A purpuric rash 
developed four days before her death which first appeared in both groins and later over both legs (see figure 4). Twelve days after admission there was a slight purulent discharge from the right ear which did not recur. The legs gradually became more spastic and the head retracted. There were frequent twitchings of both hands with an increased rigidity of the arms. The left external jugular vein became very prominent and a thick firm thrombus could be palpated throughout its entire length. The child remained drowsy with long periods of semi-consciousness, a variable temperature and gradual decline in general health until she died six weeks after admission to the hospital.

At post-mortem examination the skin showed numerous purpuric spots over the legs, arms and trunk, but most marked on the legs (see figure 4). The lungs contained several embolic infarcts and haemorrhagic areas. Both

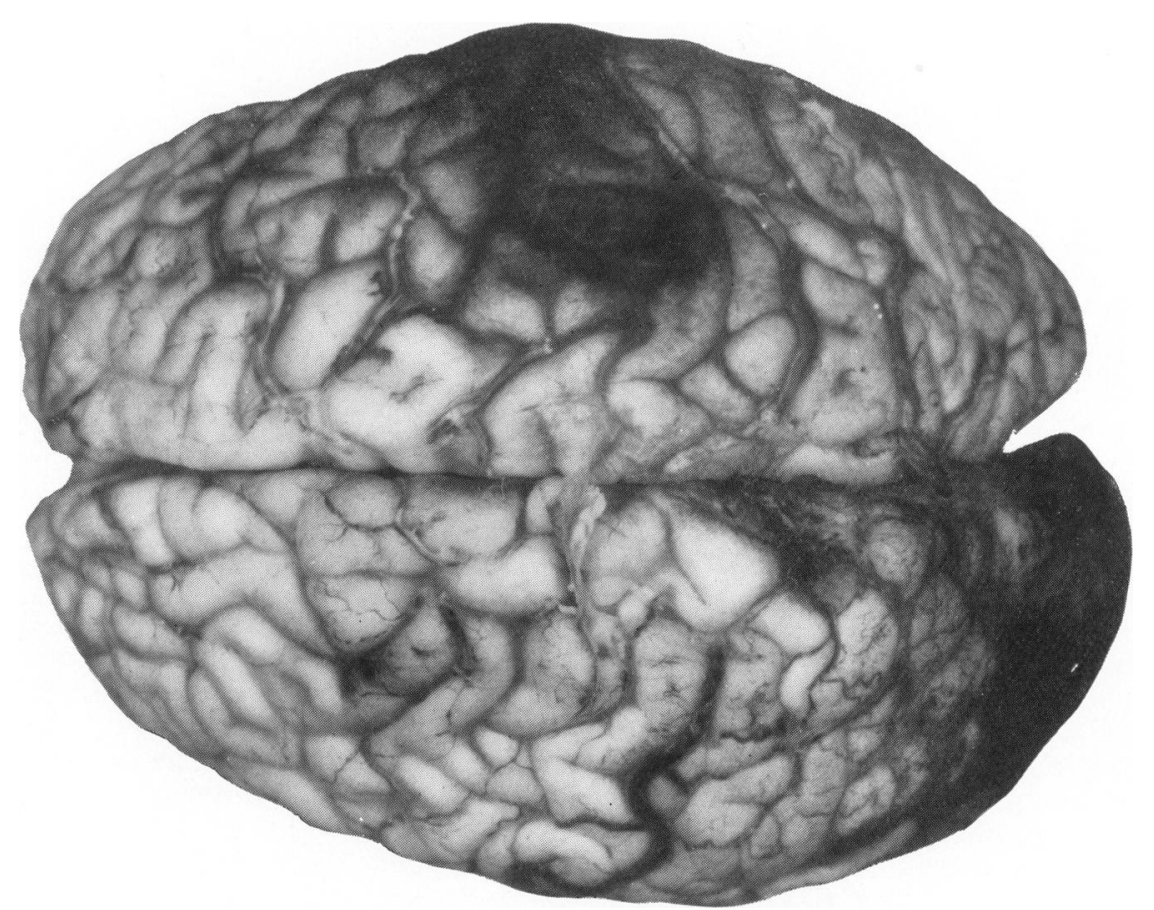

Fig. 5. Case 21. J. B.-Thrombosis of the superficial vessels and subarachnoid haemorrhage.

kidneys showed septic embolic infarcts. All of the venous sinuses of the skull were thrombosed. The thrombosis extended from the superior longitudinal sinus along the lateral sinuses and down into the jugular vein. The left external jugular vein was markedly distended and thrombosed throughout its complete length. The straight sinus, inferior saggital and veins of Galen were thrombosed. The majority of the large superficial veins showed thrombosis. There was considerable subarachnoid haemorrhage over the left occipital lobe, another over the right midparietal region and a small one over the superior surface of the right frontal lobe (see figure 5). The vessels in the left choroid plexus were completely thrombosed as were the vessels in the surrounding brain substance. There was considerable 
softening of the brain in this area (see figure 6). There was thick yellow pus present in both middle ears and mastoid antra, from which a pure culture of a haemolytic streptococcus was grown.

The outstanding feature of this case was an illness of six weeks' duration without any evidence of infection except pyelitis. Whereas at postmortem examination the mastoids were found to be grossly infected with pus which grew a haemolytic streptococcus.

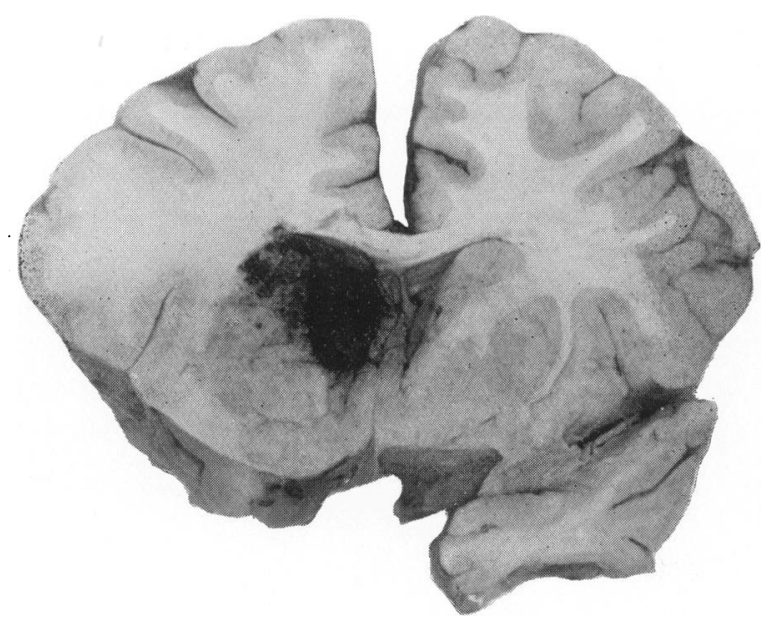

Fig. 6. Case 21. J. B.-Thrombosis of choroid plexus.

Case 22. S. W., a girl, aged two-and-a-half years, was well until four days before admission, when she became tired in the afternoon and slept for a long time. It was then noticed that she could not use her right hand and could not speak. The following day the right hand and the right side of the face showed marked twitching which continued until the day before admission. The right leg was then noticed to be motionless. The child was restless between long periods of drowsiness. In the hospital she gradually became more comatose. The temperature ranged between $100^{\circ}$ and $104^{\circ} \mathrm{F}$. The right ear drum was pale lut not bulging. There was neck rigidity and a positive Kernig sign. The right side of the face showed some weakness and the right arm was completely paralyzed and flaccid. The right leg became spastic and when touched it would go into a clonic spasm. The left side appeared normal until a few hours before death when the left hand began to twitch. The cerebro-spinal fluid contained 8 leucocytes and 17 red blood cells per c.mm. The cultures were sterile. Biochemical examination revealed sugar $70 \mathrm{mgm}$. per cent., chlorides 866 mgm. per cent. and protein $10 \mathrm{mgm}$. per cent. The plasma chlorides on the same day were $695 \mathrm{mgm}$. per cent. A throat swab grew chiefly a haemolytic streptococcus. A blood count showed haemoglobin 104 per cent., erythrocytes $5,600,000$ per c.mm., leucocytes 11,200 per c.mm. and the differential count was as follows: Polymorphonuclears 58 per cent. (30 per cent. non-segmented, 28 per cent. segmented), metamyelocytes 2 per cent., lymphocytes 36 per cent. and monocytes 4 per cent. The urine examination showed the following:-albumin-cloud; sugar-none; acetone ++ ; 
deposit-hyaline casts, occasional red blood cells, pus cells 2 or 3 per H.P.F. and a very occasional granular cast.

Post-mortem examination revealed a well-nourished child with a haemorrhagic infarct in the upper pole of the right kidney with an area of softening surrounding it. The cerebral venous sinuses showed no evidence of thrombosis. There was some thrombosis of the branches of the Sylvian vein and the vessels over the left parietal region. The sulci in this region showed thrombosis of the vessels on the suface of the cortex with slight subarachnoid haemorrhage and a haemorrhagic necrosis in the surrounding brain tissue. The other vessels of the brain were engorged, but no other thromboses were found. There was pus in the right middle ear and mastoid antrum which was cultured and grew a haemolytic streptococcus.

The above four cases have each shown an unusually high level of chloride in the cerebro-spinal fluid. A summary of the cerebro-spinal fluid findings is given in table 3 .

Case 23. S. S., a boy, aged ten months, had been a normal breast-fed infant until three months before admission, when he began to sleep for lengthening periods until finally he could be aroused only with difficulty. $\mathrm{He}$ developed a cough and bronchitis three weeks before admission to the hospital. Examination revealed a well-developed and well-nourished pale infant with irregular respirations. He was listless and drowsy, and disinterested in his surroundings. The eyes following a bright light and the pupils reacted slowly. The discs were normal. There was a slight stiffness of the neck. The limbs moved occasionally with stimulation but they appeared weak, the legs being weaker than the arms. Muscle tone was decreased and the reflexes were absent. Plantar response was extensor and the Kernig sign negative. There was twitching of both arms and legs for a short time after admission to the hospital. A lumbar puncture was performed and clear cerebro-spinal fluid was withdrawn under no increase of pressure. The cell count was 3 leucocytes per c.mm. The chemical analysis revealed-sugar $25 \mathrm{mgm}$. per cent., chlorides $680 \mathrm{mgm}$. per cent. and protein $13 \mathrm{mgm}$. per cent. In view of these findings further spinal punctures were not performed. The fatty acid, cholesterol and phospholipoid estimations in the blood were within normal limits. The serum calcium was $9 \cdot 8 \mathrm{mgm}$. per cent. Four days after admission the child developed a temperature of $104^{\circ} \mathrm{F}$. which subsided to $100^{\circ}$ and $101^{\circ} \mathrm{F}$., and was associated with a right otitis media which did not appear severe. The child's mental condition appeared to improve at times when he would take his feeds better and occasionally be interested in his surroundings. A blood count showed:Haemoglobin 62 per cent., erythrocytes 3,500,000 per c.mm., leucocytes 3,800 per c.mm. Differential-Neutrophil polymorphonuclears, segmented, 12 per cent.; neutrophil polymorphonuclears, non-segmented, 12 per cent.; eosinophil polymorphonuclears, segmented, 1 per cent.; lymphocytes, large, 46 per cent.; lymphocytes, small, 23 per cent.; lymphocytes, immature, 2 per cent.; monocytes 4 per cent. Two normoblasts were found in counting 100 leucocytes. There was some anisocytisis.

At post-mortem examination a terminal bronchopneumonia was found in both lower lobes. On opening the skull the dura mater was found to be thickened and adherent to the bone. The convolutions of the brain appeared shrunken and the sulci very prominent. All of the superficial vessels appeared to be distended and thrombosed. There was an excess of cerebro-spinal fluid over the surface. All of the cranial venous sinuses contained an old-standing thrombosis (fig. 7). The accessory nasal sinuses were all found to be healthy, and also the left middle ear and mastoid 
antrum. The right middle ear and mastoid antrum and cells contained thick pus, which grew a haemolytic streptococcus. Cultures of the thrombus were sterile.

The possibility of some previous meningeal irritation which would account for the lethargy and drowsiness for three months could not be ruled out in this case. The more reasonable explanation, however, would appear to be a partial thrombosis from the onset, possibly due to a respiratory infection which was not recognized by the parents.

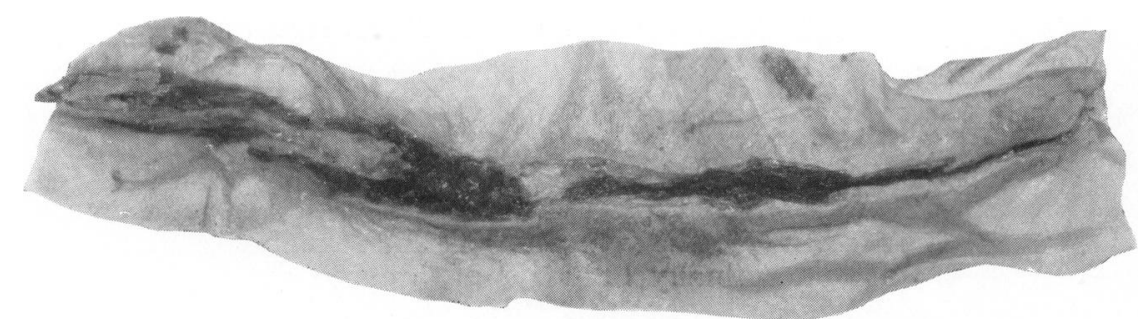

FIG. 7. Case 23. S. S.-Thrombus lying in exposed superior longitudinal sinus.

Case 24. I. H., a boy, aged nine months, suffered with post-basal meningitis for about six weeks before his admission to the hospital. The head became hydrocephalic with some retraction. The cerebro-spinal fluid contained 330 cells per c.mm., sugar nil, chlorides $617 \mathrm{mgm}$. per cent. and protein $127 \mathrm{mgm}$. per cent.

At post-mortem examination a chronic basal meningitis with marked internal hydrocephalus was found. The left lateral sinus was partially thrombosed as a result of an acute mastoid infection on that side.

This case illustrates the changes which are found in the cerebro-spinal fluid due to the original disease, in this case meningitis. Here the thrombosis of the lateral sinus was of recent origin and probably resulted from an acute mastoid infection. There were not any clinical signs which would suggest the presence of sinus thrombosis.

Case 25. I. C., a boy, aged seven months, was a normal infant who became sleepless and developed uncontrolled movements of the legs and tongue. He was found to have an external strabismus, slight neck rigidity and a positive Kernig sign on each side. The limbs were hypertonic and the reflexes brisk. Chvostek's and Trousseau's signs were negative. The child developed a convulsion in which the limbs were extended, the face was distorted and there was marked cyanosis. Later the right arm and shoulder was noted to be twitching. A lumbar puncture was performed daily for three days, the first one showed only a few red blood cells. The third specimen contained 12 leucocytes per c.mm., sugar 54 mgm. per cent., chlorides $696 \mathrm{mgm}$. per cent. and protein $40 \mathrm{mgm}$. per cent. The child's condition was variable, at times approaching normal, but usually extremely restless. Finally the head became retracted, vomiting forceful, both legs rigid, the head bathed in perspiration and the child screamed continuously unless under the influence of sedative. He finally died four weeks after his admission to the hospital and five weeks after the onset. 
Fig. 8. Case 25. I. C.-Vault of skull. Thrombosis of the veins draining into the superior logitudinal sinus.

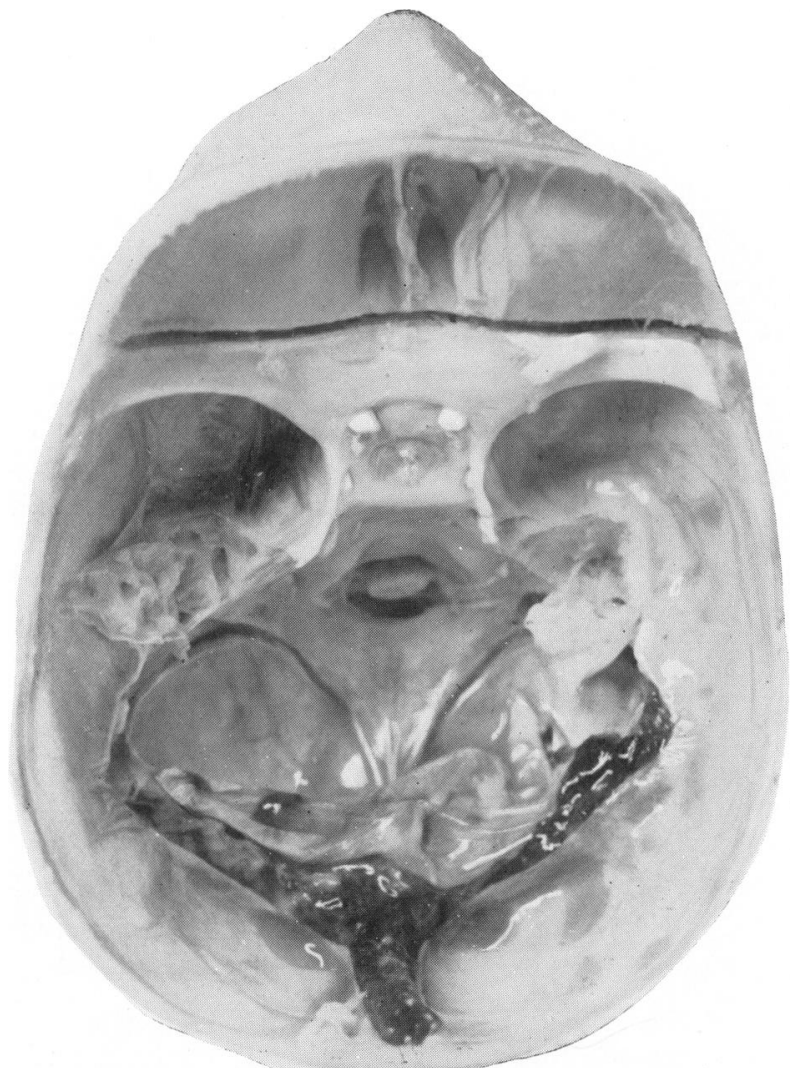


At post-mortem examination the vessels over the surface of the brain showed an extensive thrombosis. All of the cerebral venous sinuses showed some thrombosis, which extended along the lateral sinuses and into the right jugular foramen (fig. 8 and 9). Both middle ears contained a moderate amount of thin purulent material. Cultures of this material grew an haemolytic streptococcus and haemolytic staphylococcus albus.

Case 27. P. J., a girl, aged eight months, was a well-developed and well-nourished infant, perfectly well until one week before being sent to hospital, when she became drowsy and vomited occasionally. Later she became very restless and pallor was noticed. The legs twitched occasionally and finally became stiff. Examination revealed a positive Kernig sign on both sides and the neck was rigid. The knee jerks were present and equal. Pus cells and albumin were found in the urine. The cerebro-spinal fluid contained 35 leucocytes per c.mm. and 62 red blood cells per c.mm. A differential count of the leucocytes showed 60 per cent. polymorphonuclears and 40 per cent. mononuclears. Cultures were sterile. A blood count revealed a hypochromic anaemia:- Haemoglobin 45 per cent., red blood cells 3,520,000 per c.mm., colour index 0.64 and leucocytes 19,000 per c.mm. After showing an irregular, septic temperature for four days the child died with generalized convulsions and cyanosis. At post-mortem examination the superior longitudinal sinus and the cerebral vessels draining into it showed an extensive thrombosis (fig. 10). There was an area of sub-

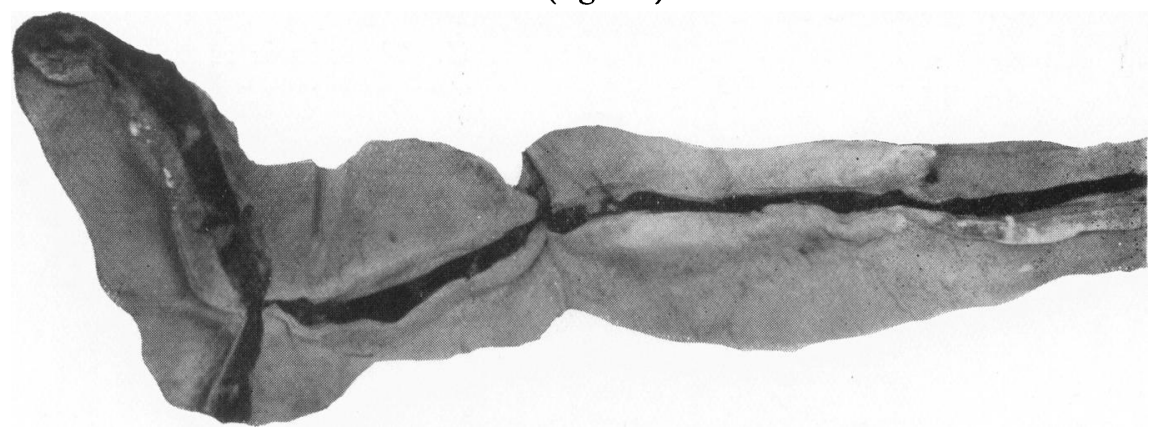

Fig. 10. Case 27. P. J.-Thrombus exposed by opening the superior

arachnoid haemorrhage over the upper part of the left Rolandic area. Both middle ears and the mastoid antra contained thick creamy pus. The kidneys showed several pyaemic abscesses. Cultures of material from the ears grew H. influenzae and pus from the kidney grew B. coli.

\section{Symptomatology}

A study of the eight cases which have been summarized reveals a number of common signs which have assisted in arriving at a proper diagnosis. The usual history obtained is one of a previously healthy child who suddenly becomes drowsy or tired with periods of extreme restlessness followed by convulsions or localized twitchings of some part of the body. The story then goes on to paresis of limbs, face, tongue or eye muscles and sometimes marked spasticity. Rhythmic movements and clonic spasms were frequent and vomiting and feverishness were complained of in several instances. A stiff neck, with or without head retraction, a positive Kernig sign and absent reflexes were usual findings. A marked purpuric rash developed, 
chiefly over the skin of the extremities in three children. A not uncommon observation was irregular breathing and irregular pulse. The variability of the mental state and periods of semi-consciousness or unconsciousness were sometimes outstanding features. The temperature was extremely variable. Thus in case 19 the temperature remained at $102^{\circ} \mathrm{F}$. throughout the illness, whilst in case 20 it remained normal or subnormal except on two readings when it reached $100^{\circ} \mathrm{F}$. The former showed far less evidence of infection post mortem than the latter. Case 27 ran a swinging, high temperature throughout, which was explained by the findings at autopsy of pyogenic abscesses in the kidneys and gross infection of the mastoids and sinuses. All patients developed some elevation of temperature during the course of the illness, but this was often intermittent.

The above signs and symptoms are by no means confined to cerebral sinus thrombosis, nor do they occur in every patient. However, they occurred sufficiently often in this small series of cases that the condition was usually considered in the differential diagnosis. Those cases associated with direct extension from a mastoiditis to the lateral sinus, or of infection of the face into the cavernous sinus, usually present a group of symptoms which are more easily recognized and which are described in standard textbooks. These sinuses are not connected directly with the vessels which drain the brain, and therefore if they become blocked there are alternative routes for the return flow of blood, and severe cerebral symptoms do not usually occur. Thrombosis associated with meningitis is usually marked by the primary disease. The other cases form a group which show the foregoing signs and symptoms sufficiently often to produce a syndrome which should be considered in the differential diagnosis of cerebral conditions in children.

\section{Differential diagnosis}

The other cerebral conditions which give rise to signs and symptoms resembling sinus thrombosis are meningitis, cerebral abscess, cerebral haemorrhage, cerebral tumour and encephalitis. The most difficult of these to rule out in the diagnosis of cerebral sinus thrombosis is often cerebral haemorrhage, since there is some haemorrhage usually present with thrombosis. However, the amount of haemorrhage and therefore the number of red blood cells per c.mm. is usually much less in sinus thrombosis than in cerebral haemorrhage. The signs and symptoms are more constant with haemorrhage and usually more sudden in onset. Purulent meningitis is usually easily differentiated from sinus thrombosis, but tuberculous and post-basal meningitis present some similar findings. In purulent meningitis the fluid contains large numbers of polymorphonuclear cells. In all forms of meningitis the sugar content is reduced or absent; the chlorides are lowered, this being most marked in tuberculous meningitis; the protein is higher than in sinus thrombosis. Cerebral abscess and cerebral tumour lead to papilloedema much more frequently than thrombosis, and their onset is much slower. The clinical picture of sinus thrombosis is much more 
acute than the gradual procession of signs and symptoms in abscess and tumour. The cerebro-spinal fluid is usually unaltered in the two latter conditions. Occasionally the cell count may be slightly increased in brain abscess, but here the presence of red blood cells, xanthochromic fluid, or increased chlorides may help in making a diagnosis of sinus thrombosis. The absence of polymorphonuclear leucocytes in the cerebro-spinal fluid in encephalitis is a differential point, but the signs and symptoms are often similar to sinus thrombosis. Experimental work recently reported by Frenckner ${ }^{9}$ suggests a possible diagnostic aid by the use of x-rays and the injection of $x$-ray opaque substance into the superior longitudinal sinus. This method shows the point at which the thrombus causes obstruction, and in some cases might lead to successful operative interference. At present the prognosis is hopeless in the majority of cases unless the thrombosis is confined to the lateral sinus.

\section{The cerebro-spinal fluid}

Patients suffering from thrombosis of cerebral vessels usually present signs and symptoms which indicate a severe intracranial lesion and therefore a lumbar puncture becomes almost essential in making an accurate differential diagnosis. Reference to table 3 brings out several points in the

TABLE 3.

\begin{tabular}{|c|c|c|c|c|c|}
\hline & LEUCOCYTISS & S RED BLOOD CEILS & SUGar & Chloridis & Protein \\
\hline & per c.mm. & per c.mm. & \multicolumn{3}{|c|}{ mgm. per cent. mgm. per cent. mgm. per cent. } \\
\hline Case $19(1)$ & 6 & 1,000 & 56 & 876 & 90 \\
\hline$(2)$ & 8 & Xanthochromic & - & 932 & 125 \\
\hline Case 20 & 4 & 0 & 0 & 774 & 13 \\
\hline Case 21 & 6 & 62 & 48 & 766 & 23 \\
\hline Case 22 & 8 & 17 & 70 & 866 & 10 \\
\hline Case 23 & 3 & 0 & 25 & 680 & 13 \\
\hline Case 24 & 330 & 0 & 0 & 617 & 127 \\
\hline Case $25(1)$ & 4 & 90 & - & - & - \\
\hline$(2)$ & 6 & Slight blood tinge & - & - & - \\
\hline (3) & 20 & 1,950 & 54 & 696 & 40 \\
\hline Case 27 & 35 & 62 & - & - & 一 \\
\hline
\end{tabular}

examination of the cerebro-spinal fluid which are of considerable importance in arriving at a diagnosis of cerebral thrombosis. The leucocytes are usually within normal limits but occasionally may be slightly raised. (In case 24 the increase to 330 per c.mm. was a result of the meningitis.) A differential 
count of the leucocytes usually shows a preponderance of polymorphonuclears. Red blood cells may, or may not be present. The number of these varied from 17 to 1,950 per c.mm. in five out of the eight cases in which the fluid was examined. The presence of red blood cells, excluding traumatic haemorrhage of course, is practically always due to some degree of subarachnoid haemorrhage in the region of the thrombosed vessels. This was true in all of the cases in table 3 which showed red blood cells in the cerebro-spinal fluid, while the others with an absence of red blood cells showed no evidence of subarachnoid haemorrhage.

Greenfield and Carmichael ${ }^{11}$ state that every case of cerebral thrombosis is associated with some haemorrhage from capillaries and that this accounts for the few red blood cells and the not uncommon finding of xanthochromic fluid. Ehlers and Courville ${ }^{3}$ emphasize the importance of a bloody or xanthochromic fluid in the diagnosis.

The chemical changes in the cerebro-spinal fluid were particularly interesting. The amount of sugar present varied from normal to a complete absence and in the presence of meningitis the sugar was lowered or completely absent. Unless complicated by meningitis the cerebro-spinal fluid proteins were within normal limits or slightly raised, the values tending to be higher in those specimens which contained red blood cells. There is usually no record of the chloride content of the spinal fluid in the cases which have been reported in the literature. It will be seen that the majority of the cases in this series in which estimations were made on the cerebro-spinal fluid the chlorides reached a high level. This occurred sufficiently often to make it almost diagnositic. In four cases the high value for chloride suggested the possibility of cerebral sinus thrombosis. Figures of 876,932 and $866 \mathrm{mgm}$. per cent. are strikingly high and have not been encountered in other conditions in children. An analysis of one thousand cerebro-spinal fluid chloride estimations carried out in this hospital reveals no figures as high as these. Neale and Esslemont ${ }^{12}$ working in this hospital found the chloride values in non-meningitic cases varied from $696 \mathrm{mgm}$. per cent. to $783 \mathrm{mgm}$. per cent. with average of $730 \mathrm{mgm}$. per cent. Greenfield and Carmichael $^{11}$ give the normal range of cerebro-spinal fluid chlorides as 720 to $740 \mathrm{mgm}$. per cent., and state that a chloride value above 750 indicates renal deficiency with impermeability to chlorides. A histological study of the kidneys in these cases of cerebral sinus thrombosis has not revealed any changes which might explain an impermeability to chlorides. Whilst Neale and Esslemont ${ }^{12}$ showed that the amount of chloride in the cerebro-spinal fluid varies to some degree with that in the blood, the administration of sodium chloride solutions intravenously, or by other routes, will not explain the high figures, since only two of the patients received rectal saline. Blacklock and Morris ${ }^{13}$ have recently reported interesting work on experimental chloride retention in rabbits. They have shown that there is a retention of chloride in heart, liver, brain and skeletal muscle in the presence of acute infection. The possibility of this retention being due to the kidneys becoming less permeable to chloride is, in their opinion, difficult to believe 
because the kidney has not lost its ability to concentrate and excrete urea and other substances. This seems to be borne out in case 21, whose blood fortunately was examined at the same time as the cerebro-spinal fluid. The cerebro-spinal fluid chlorides were $766 \mathrm{mgm}$. per cent., while the blood urea was $23 \mathrm{mgm}$. per cent. and the non-protein nitrogen $21 \mathrm{mgm}$. per cent.

\section{Causation of thrombosis}

Byers and Hass ${ }^{5}$ have reviewed many possible etiological factors in the mechanism of thrombosis, such as the severe loss of fluids in diarrhoea and vomiting and the associated polycythemia in some cases. The administration of blood and other fluids has been suspected as a possible cause of thrombosis, but the above authors found that not all of their patients had received such treatment, nor could they find evidence of destruction of the endothelial lining by bacteria or toxins. Simpson ${ }^{7}$ felt that intravenous therapy via the anterior fontanelle into the superior longitudinal sinus played a large part in the formation of thrombosis in some of his cases. Case 17 in this series received a blood transfusion by this route, but the others had not received any intravenous therapy which could be of etiological significance. Ashchoff ${ }^{10}$ speaks of the relation of the blood flow to the formation of thrombi, and slowing of the blood from various causes is favoured by Byers and Hass $^{5}$ as the most important etiological cause.

Although there was not an opportunity to carry out any special studies in the present series of cases, in view of the above theories several facts seem to be of importance. In the first place, none of the children had suffered any appreciable loss of body fluids before the signs of thrombosis were well established. None was associated with diarrhoea although in a few instances occasional vomiting occurred in the early stages of the illness. Intravenous therapy had not been used in any of the cases and thrombosis has never been found at post-mortem examination on several hundred patients who have received intravenous therapy. The extremely sudden onset of symptoms in the majority of these cases pointed to the early establishment of a thrombus and does not fit in with any theory of dehydration or stagnation of blood in the sinuses. Every patient showed evidence of some septic process at post mortem, even though it was not demonstrable during life, and this appears to be the only common factor. Why such infections should produce changes in sinus wall, which cannot be demonstrated, but which give rise to thrombosis, is difficult to explain, especially when it is considered that in a high proportion of children infection in some part of the body and usually in the middle ears is found at autopsy. It is recognized that convulsions are not uncommon during this age period in association with infections sometimes of a trivial nature; and it is conceivable that convulsions might have preceded the thrombosis in some of these cases, possibly producing conditions favourable to thrombus formation in the sinuses. Thrombosis is occasionally attributed to anaemia. An anaemia was present in only three of the cases recorded here, the haemoglobin values being 45, 62 and 29 per cent., and its importance is difficult to assess in comparison to the presence of infection. 
A study of table 4 shows the possible etiological factors in this series of cases. Case 12 was the only one which did not have a demonstrable focus of infection, the only known factor here being a moderately severe nutritional anaemia.

\section{TABLE 4.}

Possibie etiological factors in 32 cases.

$\begin{array}{lllllll}\text { Primary Ear INFECTION } & \ldots & \ldots & \ldots & \ldots & \mathbf{9} \\ \text { EAR INFECTION FOUND P.M. } & \ldots & \ldots & \ldots & \ldots & \mathbf{9} \\ \text { ACCESSORY NASAL SINUS INFECTION } & \ldots & \ldots & \ldots & \mathbf{6} \\ \text { PURULENT INFECTION ELSEWHERE } & \ldots & \ldots & \ldots & \mathbf{7} \\ \text { PNEUMONIA } & \ldots & \ldots & \ldots & \ldots & \ldots & \mathbf{7} \\ \text { ANAEMIA } \ldots & \ldots & \ldots & \ldots & \ldots & \ldots & \mathbf{3} \\ \text { TERMINAL DIARRHOEA } & \ldots & \ldots & \ldots & \ldots & \mathbf{2} \\ \text { PUlMONARY TUBERCULOSIS } & \ldots & \ldots & \ldots & \ldots & \mathbf{1}\end{array}$

The conclusion to be drawn from these cases is that infection is probably the chief factor in the production of thrombosis, since, although it may not be detectable during life, it is nevertheless practically always found at autopsy. Toxins may be conveyed by the blood stream, producing an effect upon the vessels which leads to thrombosis.

\section{Summary}

Cerebral sinus thrombosis, although comparatively rare, appears to be increasing. Eight case summaries are reported with important facts relating to thirty-two cases recorded during fourteen years. A review of the principle signs and symptoms in these cases suggests that there is a fairly constant clinical syndrome associated with the majority of those cases which are not due to mastoiditis and cellulitis with involvement of the lateral and cavernous sinuses, respectively. There are in this group the following points which often assist in making a correct clinical diagnosis of sinus thrombosis :- Sudden onset of restlessness followed by convulsions; localization of the convulsions as shown by twitching and followed by paresis; cerebrospinal fluid findings of increased or normal pressure, cells normal or slightly increased, the presence of red blood cells or xanthochromic fluid, cultures sterile, low sugar content, high chlorides and normal or slightly raised protein. The other points in the condition are the drowsiness and semiconsciousness; the rapid decline of general health in a previously healthy child, the post-mortem findings of thrombosis of cerebral vessels and in some cases the absence of any evident infection during the course of the illness. There is practically always an infection found at post mortem. The presence of high chloride values in the cerebro-spinal fluid is emphasized as an aid in arriving at the diagnosis. Several theories have been reviewed which attempt to explain the cause of the thrombosis, but no reference has been made to treatment or detailed pathology.

Thanks are due to the Honorary Physicians of the Children's Hospital for permission to use their case records. 


\section{REFERENCES}

1. Morgagni, J. B., quoted by Byers, R. K., \& Hass, E. M., Am. J. Dis. Child., Chicago, 1933, XLV, 1161.

2. Abercrombie, John, quoted by Byers, R. K., \& Hass, E. M., loc. cit.

3. Ehlers, H., \& Courville, C. B., J. Pediat., St. Louis, 1936, VIII, 600.

4. Holt, L. E., Jnr., \& McIntosh, R., Holt's Diseases of Infancy and Childhood, tenth edition, London, 1933.

5. Byers, R. K., \& Hass, E. M., Am. J. Dis. Child., Chicago, 1933, XLV, 1161.

6. Wyllie, W. G., Brit. J. Child. Dis., London, 1924, XXI, 124.

7. Simpson, R., Canad. Med. Ass. J., Montreal, 1932, XXVI, 317.

8. Osler, W., Principles and Practice of Medicine, tenth edition, London, 1927.

9. Frenckner, P., Proc. Roy. Soc. Med., London, 1937, XXX, 413.

10. Aschoff, L., Arch. Int. Med., Chicago, 1913, XII, 503.

11. Greenfield, J. E., \& Carmichael, E. A., Cerebro-spinal Fluid in Clinical Diagnosis, London, 1925.

12. Neale, A. V., \& Esslemont, M. S., Arch. Dis. Childh., London, 1928, III, 243.

13. Blacklock, J. W. S., \& Morris, N., Jour. Path. \& Bact., Edinburgh, 1936, XLII, 329. 